Christoph Sarrazin Stefan Zeuzem

\section{Virologische und immunologische Grundlagen der Therapie der chronischen HCV-Infektion}

Virologic and Immunologic Backgrounds for the Treatment of Chronic Hepatitis C Virus Infection

\section{Zusammenfassung}

Das Hepatitis-C-Virus (HCV) ist ein hepatotropes Einzel-(+)Strang RNA-Virus, das häufig zu einer chronischen Leberentzündung führt und mit dem Risiko der Entwicklung einer Leberzirrhose und eines Leberzellkarzinoms assoziiert ist. Das HCV kodiert für drei strukturelle (Kapsid, Hüllprotein 1 und 2) und 6 nicht strukturelle Proteine (NS2, 3, 4A, 4B, 5A und 5B). Bei der HCV-Infektion werden Antikörper gegen eine hypervariable Region des Hüllproteins 2 ausgebildet, die vermutlich neutralisierende Eigenschaften haben. Bei der T-Zellantwort scheint die CD4-positive, von TH1-Zellen getragene Immunantwort von besonderer Bedeutung für den Verlauf der akuten Infektion und einer antiviralen Therapie zu sein. Die Therapie mit Interferon-alpha wird über antivirale, antiproliferative und immunmodulatorische Effekte vermittelt. Die antiviralen Wirkungen des Nukleosidanalogons Ribavirin gegenüber dem HCV sind noch nicht vollständig verstanden. Das Hüllprotein 2 (E2) sowie das NS5A-Protein scheinen für Therapieresistenzmechanismen des $\mathrm{HCV}$ verantwortlich $\mathrm{zu}$ sein. Bei In-vitro-Untersuchungen fand sich eine Hemmung der Interferon-alpha induzierten Doppelstrang-RNA-abhängigen Proteinkinase (PKR) durch Bindung an eine spezifische Region des E2- und NS5A-Proteins. Klinisch sind Mutationen im Bereich des NS5A-, nicht aber des E2-Proteins mit dem Ansprechen auf eine antivirale Therapie mit Interferon-alpha und Ribavirin korreliert.

\section{Schlüisselwörter}

Hepatitis-C-Virus · Molekularbiologie · Interferon-alpha $\cdot$ Ribavirin · Therapieresistenz

\section{Abstract}

Hepatitis C virus (HCV) is a positive single-strand RNA virus leading to chronic hepatitis with subsequent development of cirrhosis and its sequelae. HCV is coding for 3 structural (core, envelope 1 and 2) and 6 non-structural proteins (NS2, 3, 4A, 4B, 5A and 5B). Antibodies developing against the hypervariable region 1 within envelope 2 protein have neutralising effects. T cell response of CD4 positive TH1-cells is important for recovery from acute HCV infection as well as for response to antiviral therapy. Treatment of chronic HCV infection with interferon-alpha is mediated through antiviral, antiproliferative and immunomodulatory effects. Antiviral effects of the nucleoside analog ribavirin are not yet fully understood. Envelope protein 2 (E2) as well as the NS5A protein seem to be involved in interferon-alpha resistance mechanisms of HCV. Interferon-alpha induced doublestrand RNA dependent proteinkinase (PKR) is inhibited in vitro due to specific binding of E2 and NS5A protein. Clinically mutations within the NS5A protein but not within the E2 protein are positively correlated with response to interferon-alpha and ribavirin combination therapy.

\section{Key words}

Hepatitis C Virus - Molecular Biology · Interferon-Alpha - Ribavirin $\cdot$ Treatment Resistance Mechanism 
Das Hepatitis-C-Virus (HCV) ist ein Einzelstrang-RNA-Virus mit positiver Orientierung und gehört zur Familie der Flaviviridae in der Spezies Hepacivirus [1]. Es besteht aus ca. 9600 Nukleotiden. Die HCV-RNA kodiert für ein großes Polyprotein von ca. 3000 Aminosäuren in einem einzigen großen Leserahmen (open reading frame, ORF). Dieses Polyprotein wird während und nach der Translation in die einzelnen HCV-Proteine gespalten [2,3]. Am aminound karboxyterminalen Ende der HCV-RNA finden sich jeweils ca. 341 bzw. 230 Nukleotide lange, nicht translatierte Überhänge (5' und 3' nicht translatierte Regionen [NTR]). Im Bereich der hochkonservierten 341 Nukleotide umfassenden 5'-NTR ist eine interne Ribosomenbindungsstelle lokalisiert, die ohne zusätzliche eukaryontische Initiationsfaktoren die Expression des HCV-Polyproteins steuert [4]. Die 3'-NTR besteht aus einer wenig konservierten kurzen Region, gefolgt von einem poly-(U-)Trakt und einer hochkonservierten Region von 98 Nukleotiden [5]. Der große HCV-Leseraster kodiert von der 5'-NTR des Virus aus gesehen für folgende strukturelle und nicht strukturelle (NS-)Proteine: Kapsid (core, C), Hüllprotein 1 (envelope, E1), Hüllprotein 2 (E2), p7 und NS2, 3, 4A, 4B, 5A und 5B [6,7]. Die (+)-RNA des HCV dient direkt zur Translation des HCV-Polyproteins. Der Aufbau des HCV-Genoms und der entsprechenden HCV-Proteine wird anhand Abb. 1 wiedergegeben.

Aufgrund der Ungenauigkeit der RNA-Polymerase kommt es bei der Replikation des HCV zu zahlreichen Nukleotidmutationen (ca. $2 \times 10^{-3}$ Mutationen pro Nukleotidposition pro Jahr) $[8,9]$. Dadurch entstehen im Laufe einer chronischen Infektion verschiedene, gleichzeitig in demselben Individuum vorhandene HCV-Isolate, die sich in ihrer Nukleotidsequenz und gegebenenfalls auch Aminosäuresequenz unterscheiden (Quasispezies) [10-12].

Ontogenetisch hat die Replikationsungenauigkeit der HCV-RNAPolymerase zur Entwicklung von mindestens 6 verschiedenen HCV-Genotypen geführt [13], die mit weiteren phylogenetischen Analysen noch in Subtypen (a, b, c) eingeteilt werden können und die zum Teil auch eine typische geografische Verteilung aufweisen $[14,15]$.

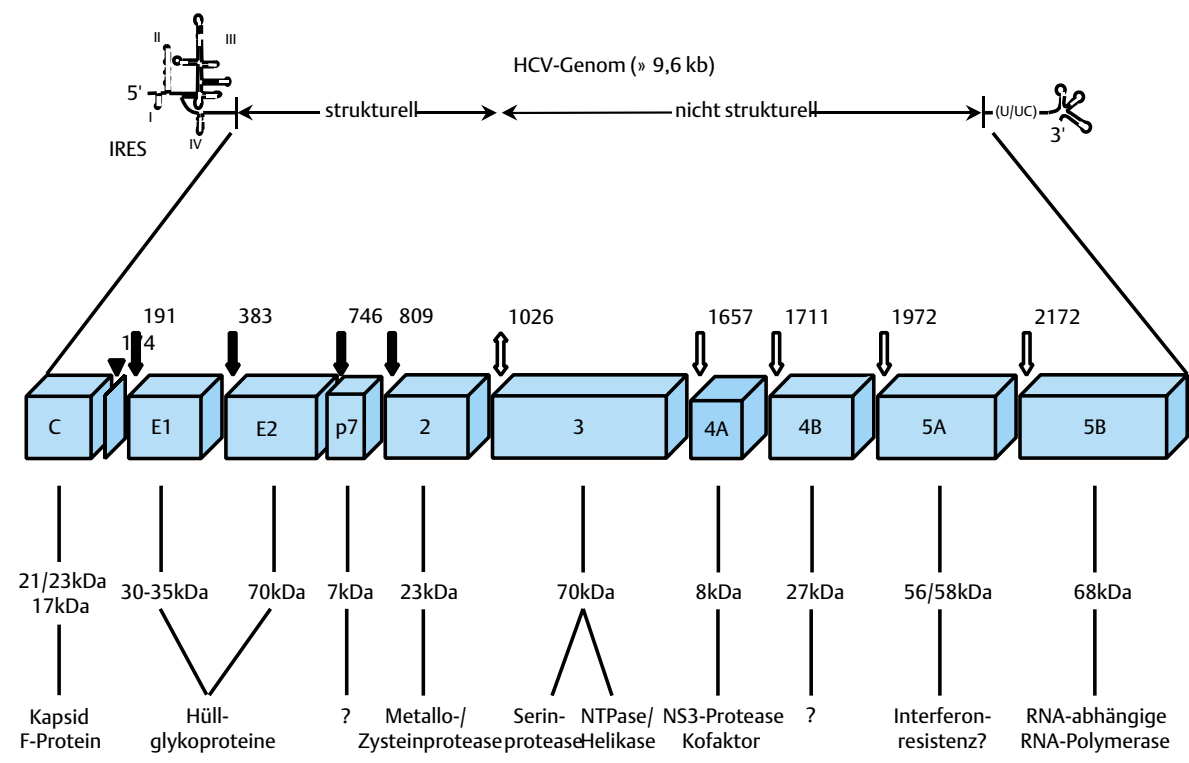

Aus dem HCV-Polyprotein werden am aminoterminalen Ende das Kapsid (C-Protein) sowie die Hüllproteine E1 und E2 mit Hilfe von wirtseigenen Proteasen abgespalten. Das C-Protein ist ein $21 \mathrm{kd}$ schweres, RNA-bindendes Phosphoprotein, das aus einem 23-kdVorläuferprotein im Zytoplasma prozessiert wird und sowohl im Zytoplasma im Bereich der Membranen des endoplasmatischen Retikulums als auch im Zellkern mit einer unterschiedlichen Sekundärstruktur lokalisiert wurde. Es wird vermutet, dass aus dem C-Protein das HCV-Nukleokapsid zusammengesetzt wird [17]. Weiterhin scheint das C-Protein in verschiedene zelluläre Prozesse einzugreifen, wobei auch onkogene Eigenschaften diskutiert werden [18].

Kürzlich wurde von der Synthese eines weiteren HCV-Proteins berichtet, das durch eine Verschiebung des Leserasters am Ribosom bei Kodon 11 des C-Proteins translatiert wird und von den Erstbeschreibern F-Protein genannt wurde. Antikörper gegen dieses 17-kd-F-Protein konnten in Seren von Patienten mit chronischer HCV-Infektion nachgewiesen werden. Eine genauere Bedeutung des F-Proteins ist bislang nicht bekannt [19].

Die beiden Hüllproteine E1 und E2 sind ca. 30-35 und $70 \mathrm{kd}$ schwere hochgradig glykosylierte Typ-I-Transmembranproteine, die als Heterodimere sowohl über eine Disulfidbrücke als auch in einer nicht kovalenten Bindung vermutlich HCV-Viruspartikel ausbilden [6,20,21]. Innerhalb des E2-Proteins findet sich am aminoterminalen Ende eine hypervariable Region (HVR1) [22,23], die bei der Chronifizierung der HCV-Infektion eine Rolle spielen könnte $[24,25]$. Karboxyterminal befinden sich dagegen sowohl im E1als auch im E2-Protein hydrophobe Ankerdomänen, die für die Integration in die Membran des endoplasmatischen Retikulums von Bedeutung sind $[6,26]$. Von dem hydrophoben $7 \mathrm{kd}$ schweren Protein p7, das nicht vollständig vom E2-Protein abgespalten wird, ist bislang eine genauere Funktion nicht bekannt. Am karboxyterminalen Ende des p7 beginnen die nicht strukturellen HCV-Proteine.

Abb. 1 HCV-Genomorganisation. Die Pfeile geben die Schnittstellen des Polyproteins wieder (Aminosäurenzählung nach dem HCV-1b-Prototyp HCV-J) [16]. 
Die NS2/3-Bindungsstelle wird durch eine Autoproteinasefunktion gespalten, während die übrigen nicht strukturellen Proteine durch die NS3/4A-Proteinase prozessiert werden [3]. Das hydrophobe, ca. 23 kd schwere NS2-Protein scheint als wesentliche Funktion diese autokatalytische Spaltung an seinem karboxyterminalen Ende zu enthalten, die Charakteristika einer Metallo- als auch einer Zysteinprotease aufweist [27-29]. Das $70 \mathrm{kd}$ schwere NS3-Protein enthält im aminoterminalen Drittel eine Serinprotease, die an der autokatalytischen NS3/4A-Spaltung beteiligt ist und auch für die Prozessierung der übrigen nicht strukturellen HCV-Proteine verantwortlich ist. Für die NS4A/B-, 4B/5A- sowie $5 \mathrm{~A} / \mathrm{B}$-Spaltung geht das NS3-Protein einen stabilen Komplex mit dem NS4A-Protein ein [2,30,31]. Im Bereich der karboxyterminalen zwei Drittel des NS3-Proteins ist dagegen eine Nukleosidtriphosphatase (NTPase)/RNA-Helikase-Domäne lokalisiert, die vermutlich bei der Replikation der HCV-RNA zur Entwindung von Sekundärstrukturen gebraucht wird [32-34]. Das lediglich 54 Aminosäuren umfassende, $8 \mathrm{kd}$ schwere NS4A-Protein bildet den funktionell wichtigen Kofaktor der NS3/4A-Proteinase $[2,35]$. Daneben ist es an der Phosphorylierung des NS5A-Proteins beteiligt $[36,37]$. Über die Bedeutung des hydrophoben, 27 kd schweren NS4B-Proteins ist bislang sehr wenig bekannt. Eine Interaktion mit der Virusreplikation wird vermutet. Das überwiegend hydrophile NS5A-Protein existiert nach verschiedenen Phosphorylierungen als 56 und 58 kd schwere Form $[38,39]$ und scheint neben möglichen transaktivierenden und weiteren Funktionen auch eine Interferonresistenz-vermittelnde Wirkung aufzuweisen, die weiter unten näher beschrieben wird [40-43]. Das 68 kd schwere, zytoplasmatisch perinukleär lokalisierte NS5B-Protein weist u.a. mit dem GDD-Motiv hochkonservierte Sequenzen auf, die für eine Funktion als RNA-abhängige RNA-Polymerase typisch sind. Eine nicht HCV-spezifische RNA-Polymeraseaktivität sowie eine im Bereich von karboxyterminal gelegenen Aminosäuren befindliche perinukleäre Ankerdomäne konnten In vitro demonstriert werden [44-49].

\section{Immunbiologie des HCV}

Nach einer akuten Infektion mit dem Hepatitis-C-Virus kommt es zunächst zu einer unspezifischen Immunreaktion, die von natürlichen Killerzellen, neutrophilen Granulozyten und Makrophagen getragen wird. Parallel kommt es zur Aktivierung einer spezifischen Immunantwort der T- und B-Lymphozyten über Antigenpräsentierende Zellen. Im Rahmen der humoralen Immunantwort werden Antikörper gegen verschiedene strukturelle und nicht strukturelle HCV-Proteine gebildet. Eine Kreuzreaktion im Bereich eines HCV-Kapsidepitops mit einem Wirtsprotein wurde beschrieben und führte zu Vermutungen über eine potenzielle Induktion einer Autoimmunreaktion als Folge dieser so genannten molekularen Mimikry [50,51]. Antikörper, die gegen ein Epitop im Bereich der hypervariablen Region (HVR 1) des E2-Hüllproteins ausgebildet werden, haben möglicherweise neutralisierende Eigenschaften, da sie in Untersuchungen mit Schimpansen eine HCV-Infektion verhindern konnten [52]. Die sich relativ rasch ändernden Sequenzen im Bereich dieser hypervariablen Region des E2-Proteins könnten bei der Chronifizierung der HCV-Infektion eine Rolle spielen [52]. Weiterhin werden Antikörper auch gegen die nicht strukturellen HCV-Proteine ausgebildet. Eindeutige Antikörper-
Konstellationen zu bestimmten Phasen der HCV-Infektion, die zum Beispiel eine frische oder abgelaufene Infektion anzeigen würden, existieren nicht $[53,54]$. Dagegen konnten bei der T-Zellantwort des Wirtes typische Reaktionen nachgewiesen werden, die bei einer akuten HCV-Infektion mit einer spontanen Ausheilung bzw. einer Chronifizierung der Erkrankung einhergingen. So fand sich bei Patienten mit einer spontanen Elimination des HCV eine von Antigen präsentierenden Zellen durch HLA-Klasse II vermittelte CD4-positive T-Zellantwort mit überwiegender Produktion von Interferon- $\gamma$ und Interleukin-2 (TH1-Zellen), die gegen das NS3-Protein gerichtet war [55]. Diese gegen NS3 gerichtete Immunantwort war auch langfristig nach Ablauf der akuten Infektion noch nachweisbar, während bei Patienten mit einem chronischen Verlauf keine oder nur eine schwache T-Zellreaktion gegenüber dem NS3-Protein $\mathrm{zu}$ finden war, die eher eine TH2-gerichtete Zytokinproduktion aufwies [56]. Bei einer chronischen Hepatitis-C-Virusinfektion konnte eine CD4-positive T-Zellantwort in unterschiedlichem Ausmaß gefunden werden, die gegen verschiedene strukturelle und nicht strukturelle HCVProteine gerichtet war [57,58]. Bei antiviral behandelten Patienten konnte im Anschluss an eine Interferon- $\alpha$-Behandlung eine CD4-positive T-Zellantwort mit einem dauerhaften Ansprechen auf die Therapie korreliert werden. Eine CD8-positive T-Zellantwort, die über die Antigenpräsentation durch die auf allen Zellen vorkommenden HLA-Klasse-I-Moleküle vermittelt wird, wurde ebenfalls gegen verschiedene strukturelle und nicht strukturelle HCV-Proteine nachgewiesen, eine Korrelation mit dem Verlauf der HCV-Infektion fand sich jedoch nicht [59]. Allerdings konnte eine starke CD8-positive T-Zellantwort mit einer niedrigen Viruslast korreliert werden. Im Vergleich der Quasispezies des HCV in der Leber und im peripheren Blut konnten qualitative Unterschiede nachgewiesen werden [60]. Da die Proliferation der T-Zellen in Lymphknoten außerhalb der Leber induziert wird, könnten die spezifischen Rezeptoren zumindest teilweise nicht zu intrahepatischen HCV-Epitopen passen und somit zur Chronifizierung der Infektion beitragen $[61,62]$.

\section{Interferon-alpha}

Es existieren mindestens 15 verschiedene Interferon- $\alpha$-Subtypen (IFN- $\alpha 1-15)$, die im Wesentlichen von Leukozyten produziert werden. Bislang wurden mindestens 23 verschiedene Gene für die Kodierung der menschlichen alpha-Interferone gefunden, die alle auf Chromosom 9 lokalisiert sind [63]. Alpha-Interferone sind Polypeptide von 165-172 Aminosäuren mit einer Homologie von ca. 70\% zwischen den verschiedenen Subtypen. Die Subtypen unterscheiden sich überwiegend im aminoterminalen Ende des Proteins, während die Sequenz in den Aminosäuren 115-151 hochkonserviert ist. Die Ausbildung von Disulfidbrücken zwischen den Aminosäuren 1/98 und vor allem 29/138 ist bedeutsam für die antivirale Aktivität. Die antivirale Effektivität der verschiedenen Subtypen weist teilweise bedeutende Unterschiede auf. So wurde für Interferon- $\alpha 8$ die höchste antivirale Aktivität gemessen [64].

Durch Aufreinigung und Anreicherung von natürlich produzierten Interferonen und durch gentechnische Methoden können Alpha-Interferone in ausreichender Menge für therapeutische Zwecke hergestellt werden [65,66]. Drei gentechnisch hergestellte Alpha-Interferone sind für die Behandlung der chro- 
nischen Virushepatitis zugelassen: Interferon- $\alpha 2 \mathrm{a}$ und $-\alpha 2 \mathrm{~b}$ sowie ein Alpha-Interferon, das aus den jeweils am häufigsten vertretenen Aminosäuren der verschiedenen bekannten Alpha-Interferone synthetisch zusammengesetzt ist. Dieses so genannte Konsensusinterferon (Interferon-alfacon1) ist $\mathrm{zu}$ 89\% mit Interferon- $\alpha 2 b$ identisch [67]. Weiterhin werden natürlich vorkommende, von Leukozyten und Lymphoblasten produzierte Alpha-Interferone in klinischen Studien untersucht $[68,69]$.

\section{Antivirale Effekte von Interferon-alpha}

Die antiviralen Wirkungen der Interferone führten zu ihrer Entdeckung [70] und sind tatsächlich ihre wesentliche biologische Eigenschaft. Die antivirale Wirkung von Interferon tritt innerhalb kürzester Zeit auf. Es konnte gezeigt werden, dass Mäuse, die keine Interferonrezeptoren exprimieren, keine Abwehr gegenüber viralen Infekten aufweisen. Allerdings haben verschiedene Viren Mechanismen entwickelt, sich der antiviralen Abwehr der Wirtsorganismen zu entziehen, wodurch in der Evolution wiederum neue antivirale Mechanismen im Wirt entstanden sind. Es gibt daher mehrere zelluläre antivirale Effektormechanismen, die durch Interferone aktiviert werden. Drei verschiedene Mechanismen der antiviralen Interferonwirkung sind näher bekannt [71].

Die Expression der Doppelstrang-RNA-abhängigen Proteinkinase (PKR) wird vorwiegend durch Interferon- $\alpha / \beta$ stimuliert. Nach Bindung der PKR an Doppelstrang-RNA kommt es intrazellulär zu einer Aktivierung der PKR durch Autophosphorylierung. Die aktivierte PKR phosphoryliert den Initiationsfaktor der Proteinbiosynthese eIF2 an der $\alpha$-Untereinheit. Normalerweise hat eIF2 die zentrale Aufgabe, Met-tRNA zur 40S-Untereinheit des Ribosoms zu transportieren und damit die Translation zu initiieren. Dabei wird jeweils an eIF2 gebundenes GDP durch GTP mit Hilfe des Enzyms eIF2B ausgetauscht. Durch die Phosphorylierung von eIF2 $\alpha$ entsteht jedoch ein inaktiver Komplex aus eIF2-GDP und eIF2B am Ribosom, der die Translation inhibiert. Es scheint dabei eine relative Selektivität für die Hemmung der viralen Translation zu bestehen, da einige wichtige zelluläre Proteine weiter exprimiert werden. Weitere Wirkungsmechanismen der PKR sind die Beeinflussung der zellulären Transkription über eine Aktivierung des nukleären Faktors (NF) $\kappa B$ durch die Phosphorylierung des Inhibitionsfaktors (I) $\mathrm{kB}$ sowie die Auslösung einer TNF $\alpha$-vermittelten Apoptose [71].

Die 2'-5'-Oligoadenylatsynthetase wird durch Interferon- $\alpha$, $-\beta$ und $-\gamma$ stimuliert und führt in Gegenwart von Doppelstrang-RNA zur Produktion von 2'-5'-Oligoadenylaten, die die RNase L aktivieren. RNase L spaltet Einzelstrang-RNA, wodurch virale RNA zerstört werden kann. Weiterhin kommt es zur Degradation ribosomaler RNA mit der Folge der Ribosominaktivierung und damit Hemmung der Proteinbiosynthese. Die wesentliche Bedeutung der RNase-L-vermittelten antiviralen Wirkung wurde durch fulminante Virusinfektionen in RNase-L-„Knock-out“-Mäusen nachgewiesen $[65,71]$.

Proteine, die aufgrund einer vererbten Resistenz von bestimmten Labormäusen gegen Viren der Orthomyxogruppe entdeckt und Mx-Proteine (nach Myxoviren) genannt werden, sind weitere Effektoren der Interferone. Mx-Proteine wurden in allen bislang untersuchten Wirbeltieren gefunden. Sie interferieren direkt mit der Virusreplikation und beeinflussen die virale
Transkription (Mx1 und MxA). Möglicherweise kommt es auch zu einer direkten Interaktion mit viralen Polymerasen. Wie die PKR werden Mx-Proteine vorzugsweise von Typ-I-Interferonen aktiviert [71].

\section{Antiproliferative Effekte von Interferon-alpha}

Durch Beeinflussung verschiedener, für den Zellzyklus wichtiger Gene (c-myc, pRB, cyclin D3, cdc25A), die u. a. über die PKR reguliert werden, kann das Zellwachstum durch Interferone gehemmt werden. Bei verschiedenen Tumoren wird diese Interferonwirkung therapeutisch eingesetzt. Auf den kontrollierten Zelltod haben Interferone in Abhängigkeit des Stadiums der Zelldifferenzierung hemmende als auch aktivierende Eigenschaften. Das Zusammenspiel der verschiedenen beteiligten zellulären Proteine wird bisher nicht vollständig verstanden [71].

\section{Immunmodulatorische Effekte von Interferon-alpha}

Interferon-alpha führt zu einer verstärkten zellulären Expression von MHC-Klasse-I-Proteinen, die virale Antigene präsentieren und T-Zellen aktivieren. Durch eine Stimulation der Produktion der MHC-Klasse-I-bindenden Proteasomen auf die Gabe von Interferon kommt es zusätzlich zu einer qualitativen und quantitativen Steigerung des antigenen Peptidrepertoirs der Zelle. Ebenfalls kommt es zu einer direkten Aktivierung der humoralen Immunantwort durch eine Steigerung der Entwicklung und Proliferation von B-Zellen und der Immunglobulinausschüttung [71].

\section{Ribavirin}

Ribavirin (1- $\beta$-D-Ribofuranosyl-1,2,4-triazol-3-carboxamid) ist dem Ribonukleosid Guanosin analog mit dem Unterschied, dass die D-Ribose statt Purin den 1,2,4-Triazol-3-carboxamidrest in $\beta$-Konfiguration am C1-Atom der Ribose trägt. Die Synthese von Ribavirin geht auf das Jahr 1972 zurück, als verschiedene Nukleosidanaloga auf ihre antiviralen Eigenschaften hin untersucht wurden [72]. Es ist eine gut wasserlösliche Substanz mit einem Molekulargewicht von 244 Da und antiviraler Aktivität gegen verschiedene DNA- und RNA-Viren bei In-vitro- und In-vivo-Untersuchungen $[73,74]$. Ribavirin wird nach zellulärer Aufnahme in die aktiven 5'-Mono-, Di- und Triphosphate metabolisiert, reichert sich im Körper mit einer Halbwertszeit von bis zu 40 Tagen insbesondere in den Erythrozyten an und wird vorwiegend renal ausgeschieden [75]. Die genaue Wirkungsweise von Ribavirin ist nicht bekannt. Es wurden jedoch drei verschiedene antivirale Wirkungsmechanismen beschrieben.

Im Anschluss an die Transkription wird bei Eukaryonten und vielen Viren eine weitere Prozessierung der entstandenen mRNA vorgenommen. Dabei wird vom 5'-Triphosphatende der mRNA zunächst durch Hydrolyse ein Phosphatrest durch Guanosinmonophosphat ersetzt. Durch Methylierung des N-7-Stickstoffs des endständigen Guanins entsteht das als „cap“ bezeichnete charakteristische 7-Methylguanylat am 5'-Ende der mRNA. Diese "caps“ stellen nicht nur einen Schutz der mRNA gegen einen Abbau durch Phosphatasen und Nukleasen dar, sondern sind auch für eine Verstärkung der Effektivität der folgenden Translation verantwortlich. Für das aktive, aus Ribavirin in vivo gebildete Ribavirin-5'-triphosphat wurde In vitro eine Hemmung der Methylierung der mRNA von Vaccinaviren gezeigt, die mit einer Ver- 
minderung der Translation und einer Abnahme viraler zytopathogener Effekte In vitro einhergeht [76].

In einer anderen Arbeit konnte durch Ribavirin In vitro eine Hemmung der Influenzavirus-kodierten Proteinbiosynthese gezeigt werden. Als Ursache fand sich eine Verminderung der intrazellulär messbaren Menge an Guanosintriphosphat (GTP), das für den Einbau in die RNA bei der Replikation und Transkription benötigt wird. Da sich jedoch die Hemmung der Synthese der viralen Proteine durch eine Zugabe von GTP im Überschuss nicht vollständig aufheben ließ, wurde auf eine zusätzliche direkte Interaktion mit der viralen Replikation geschlossen [77]. Als Ursache der Verminderung des zellulären GTP wurde eine Hemmung der Inosinmonophosphatdehydrogenase sowie der Thymidinkinase, die beide bei der GTP-Synthese beteiligt sind, durch Ribavirin nachgewiesen [75]. Für eine direkte Hemmung der viralen Replikation als möglichen weiteren Wirkungsmechanismus sprachen In-vitro Versuche mit Influenzaviren, bei denen die virale RNAabhängige Polymerase selektiv durch Ribavirintriphosphat gehemmt werden konnte [78]. Allerdings konnte in Untersuchungen mit anderen Viren keine direkte Hemmung der RNA- oder DNA-Polymerase nachgewiesen werden [76].

Neben diesen antiviralen Wirkungen des Ribavirins wurden antiproliferative und immunsuppressive Eigenschaften in Untersuchungen beschrieben, die möglicherweise ebenfalls mit der Reduktion des zellulären GTP im Zusammenhang stehen. Dabei fanden sich eine Hemmung des Tumorwachstums bei Mäusen In vivo sowie eine Beeinflussung der primären Immunantwort durch verzögerte Antikörperproduktion und T-Zellproliferation $[79,80]$. Auch in einer neueren Arbeit von Hultgren et al. konnte eine wesentliche immunmodulatorische Wirkung des Ribavirins In vitro und In vivo nachgewiesen werden. Dabei zeigte sich eine dosisabhängige Hemmung der mRNA-Konzentration von Th1und Th2-Helferzellantwort-induzierenden Zytokinen (Interleukin 2 und 4 bzw. TNF- $\alpha$ ) [81]. Diese immunologischen und weniger direkt antiviralen Wirkungen des Ribavirins könnten auch dafür verantwortlich sein, dass durch Ribavirin die antivirale Effektivität von Interferon- $\alpha$ potenziert wird, aber es bei der Behandlung der chronischen Hepatitis C mit Ribavirin allein zu keiner wesentlichen Veränderung der Viruskonzentration oder der Quasispeziespopulation kommt [81 - 85].

\section{HCV-Therapieresistenzmechanismen}

Der HCV-Genotyp 1 weist im Vergleich zu anderen Genotypen schlechtere Ansprechraten bei einer Therapie mit Interferon- $\alpha$ auf [86]. Sequenzvergleiche von japanischen interferonsensitiven und -resistenten HCV-1b-Isolaten zeigten, dass die Aminosäuresequenzen zwischen Kodon 2209 und 2248 (so genannte Interferon-Sensitivität-determinierende Region, ISDR) innerhalb des karboxyterminalen Endes des nicht strukturellen (NS)5A-Proteins charakteristische Unterschiede aufweisen. HCV-1b-Isolate mit vier oder mehr Mutationen in der Region gegenüber der HCV1b-Prototypsequenz erwiesen sich als interferonsensitiv, während HCV-1b-Prototypisolate interferonresistent waren. Isolate mit ein bis drei Aminosäurenveränderungen zeigten ein variables Ansprechverhalten auf Interferon- $\alpha$. Die häufigste Mutation fand sich im Kodon 2218: Interferon- $\alpha$-resistente Isolate wiesen ein Histidin (Prototypsequenz) auf, während interferonsensitive Iso- late an der Position häufig einen Austausch Histidin/Arginin aufwiesen [87]. Dieser Zusammenhang konnte von anderen japanischen Arbeitsgruppen in gleicher Weise gezeigt werden, während sich zunächst eine solche Korrelation der Anzahl der Mutationen im Bereich der ISDR mit dem Therapieansprechen bei HCV-1b-infizierten Patienten in Europa und USA nicht bestätigen ließ [88-90]. Dabei war auffallend, dass HCV-Isolate mit multiplen Mutationen innerhalb der ISDR bei Patienten aus westlichen Ländern vergleichsweise zu japanischen Patienten wesentlich seltener zu finden waren. In neueren Studien konnte anhand größerer untersuchter Patientenkollektive und intensivierter Therapieregime eine Korrelation der Anzahl der Mutationen im Bereich der ISDR mit dem Therapieansprechen bei HCV-1b-infizierten Patienten nachgewiesen werden. Allerdings fanden sich weiterhin bei der Mehrzahl der Patienten mit dauerhaftem virologischen Therapieansprechen lediglich 1-3 Mutationen innerhalb der ISDR [91]. Für Patienten, die mit den HCV-Subtypen HCV-1a bzw. HCV-2 infiziert sind, konnte ein ähnlicher Zusammenhang der Anzahl der Mutationen mit dem Therapieansprechen nachgewiesen werden [92,93], während bei HCV-3a-infizierten Patienten eine solche Korrelation nicht gefunden wurde [89,94].

Die virologische Bedeutung des HCV-NS5A-Proteins ist weitgehend unbekannt. Kürzlich konnte In vitro eine Interaktion zwischen dem NS5A-Protein und der Interferon- $\alpha$-stimulierten Doppelstrang-RNA-abhängigen Proteinkinase (PKR) gezeigt werden, die vermutlich über eine Bindung an eine PKR-bindende Domäne (Kodon 2209-2274 nach HCV-J) innerhalb des karboxyterminalen Teils des NS5A-Proteins vermittelt wird und zu einer Inhibition der Proteinbiosynthese führen soll. Die ISDR ist Teil dieser PKR-bindenden Domäne und durch die Einfügung von Mutationen innerhalb der PKR-bindenden Domäne konnte die NS5A/PKR-Interaktion In vitro aufgehoben werden [95]. Für die zelluläre Hemmung der PKR durch eine NS5A-Expression In vitro liegen jedoch teilweise widersprüchliche Ergebnisse vor $[96,97]$ und in Untersuchungen mit Hilfe der konfokalen Lasermikroskopie konnte eine zu erwartende Kolokalisation von NS5A-Protein und PKR nicht nachgewiesen werden [98], so dass die Bedeutung der NS5A/PKR-Interaktion als mögliche Resistenzstrategie des HCV bisher nicht eindeutig geklärt ist.

Kürzlich wurde für das Hüllprotein E2 von HCV-1a/b-Isolaten ebenfalls eine Interaktion mit der PKR über eine 12 Aminosäuren umfassende so genannte PKR/eIF2 $\alpha$-Phosphorylierungs-Homologie-Domäne (PePHD, Kodon 659-670 nach HCV-J) beschrieben. Bei den HCV-Genotypen 2 und 3 war die PKR-Bindung aufgehoben. Es wurde daher vermutet, dass die PePHD der HCV-1a/b-Isolate für die relative Interferonresistenz im Vergleich zu HCV-2und -3-Isolaten beitragen könnte [99]. Eine klinische Korrelation von Mutationen innerhalb der PePHD konnte sowohl für HCV-1bals auch für HCV-3a-Isolate ausgeschlossen werden [94].

\section{Literatur}

${ }^{1}$ Classification and nomenclature of viruses: sixth report of the international committee on taxonomy of viruses. In: Murphy FA, Fauquet CM, Bishop DHL, Ghabrial SA, Jarvis AW, Martelli GP, Mayo MA, Summers MD (Hrsg). Wien: Springer 1995; 424-426 
${ }^{2}$ Bartenschlager R, Ahlborn-Laake L, Mous J, Jacobsen H. Nonstructural protein 3 of the hepatitis $C$ virus encodes a serine-type proteinase required for cleavage at the NS3/4 and NS4/5 junctions. J Virol 1993; 67: $3835-3844$

${ }^{3}$ Bartenschlager R, Ahlborn-Laake L, Mous J, Jacobsen H. Kincetic and structural analyses of hepatitis $\mathrm{C}$ virus polyprotein processing. J Virol 1994; 68: 5045-5055

${ }^{4}$ Rijnbrand RC, Lemon SM. Internal ribosome entry site-mediated translation in hepatitis $C$ virus replication. Curr Top Microbiol Immunol 2000; 242: 85- 116

${ }^{5}$ Bartenschlager R, Lohmann V. Replication of hepatitis C virus. J Gen Virol 2000; 81: 1631 - 1648

${ }^{6}$ Reed KE, Rice CM. Overview of hepatitis C virus genome structure, polyprotein processing, and protein properties. Curr Top Microbiol Immunol 2000; 242: 55-84

${ }^{7}$ Zeuzem S, Roth WK, Herrmann G. Virushepatitis C. Z Gastroenterol 1995; 33: $117-132$

${ }^{8}$ Kurosaki M, Enomoto N, Marumo F, Sato C. Evolution and selection of hepatitis $\mathrm{C}$ virus variants in patients with chronic hepatitis $\mathrm{C}$. Virology 1994; 233: $43-50$

${ }^{9}$ Ogata N, Alter HJ, Miller RH, Purcell RH. Nucleotide sequence and mutation rate of the $\mathrm{H}$ strain of hepatitis $\mathrm{C}$ virus. Proc Natl Acad Sci USA 1991; 88: 3392 - 3396

${ }^{10}$ Gomez J, Martell M, Quer J, Cabot B, Esteban JI. Hepatitis C viral quasispecies. J Viral Hepat 1999; 6: 3-16

${ }^{11}$ Simmonds P. Variability of hepatitis C virus. Hepatology 1995; 21: $570-583$

12 Martell M, Esteban JI, Quer J, Genesca J, Weiner A, Esteban R, Guardia J, Gomez J. Hepatitis C virus (HCV) circulates as a population of different but closely related genomes: quasispecies nature of HCV genome distribution. J Virol 1992; 66: 3225 - 3229

${ }^{13}$ Simmonds P, Holmes EC, Cha TA, McOmish F, Irvine B, Beall E, Yap PL, Kolberg J, Urdea MS. Classification of hepatitis C virus into six major genotypes and a series of subtypes by phylogenetic analysis of the NS-5 region. J Gen Virol 1993; 74: 2391 - 2399

${ }^{14}$ Simmonds P. Virology of hepatitis C virus. Clin Ther 1996; 18 (Suppl B): $9-36$

${ }^{15}$ Schreier E, Roggendorf M, Driesel G, Hohne M, Viazov S. Genotypes of hepatitis $C$ virus isolates from different parts of the world. Arch Virol 1996; 11: 185-193 (Suppl)

${ }^{16}$ Kato N, Hijikata M, Ootsuma Y, Nakagawa M, Ohkoshi S, Sugimura T, Shimotohno K. Molecular cloning of the human hepatitis $C$ virus genome from Japanese patients with non-A, non-B hepatitis. Proc Natl Acad Sci USA 1990; 87: 9524-9528

17 Yasui K, Wakita T, Tsukiyama-Kohara K, Funahashi SI, Ichikawa M, Kajita T, Moradpour D, Wands JR, Kohara M. The native form and maturation process of hepatitis C virus core protein. J Virol 1998; 72: $6048-6055$

${ }^{18}$ Lai MM, Ware CF. Hepatitis C virus core protein: possible roles in viral pathogenesis. Curr Top Microbiol Immunol 2000; 242: 117-134

${ }^{19}$ Xu Z, Choi J, Yen TSB, Lu W, Strohecker A, Govindarajan S, Chien D, Selby MJ, Ou J. Synthesis of a novel hepatitis $\mathrm{C}$ virus protein by ribosomal frameshift. EMBO 2001; 20: 3840-3848

${ }^{20}$ Dubuisson J. Folding, assembly and subcellular localization of hepatitis C virus glycoproteins. Curr Top Microbiol Immunol 2000; 242: $135-148$

${ }^{21}$ Deleersnyder V, Pillez A, Wychowski C, Blight K, Xu J, Hahn YS, Rice $\mathrm{CM}$, Dubuisson J. Formation of native hepatitis $\mathrm{C}$ vius glycoprotein complexes. J Virol 1997; 71: 697 - 704

${ }^{22}$ Kato N, Ootsuyama Y, Tanaka T, Nakagawa M, Nakazawa T, Muraiso K, Ohkoshi S, Hijikata M, Shimotohno K. Marked sequence diversity in the putative envelope proteins of hepatitis C viruses. Virus Res 1992; 22: $107-123$

${ }^{23}$ Weiner AJ, Brauer MJ, Rosenblatt J, Richman KH, Tung J, Crawford K, Bonino F, Saracco G, Choo QL, Houghton M. Variable and hypervariable domains are found in the regions of HCV corresponding to the flavivirus envelope and NS1 proteins and the pestivirus envelope glycoproteins. Virology 1991; 180: $842-848$

${ }^{24}$ Kurosaki M, Enomoto N, Marumo F, Sato C. Rapid sequence variation of the hypervariable region of hepatitis $C$ virus during the course of chronic infection. Hepatology 1993; 18: 1293 - 1299

${ }^{25}$ Kato N, Ootsuyama Y, Sekiya H, Ohkoshi S, Nakazawa T, Hijikata M, Shimotohno K. Genetic drift in hypervariable region 1 of the viral genome in persistent hepatitis C virus infection. J Virol 1994; 68: $4776-4784$
${ }^{26}$ Mizushima H, Hijikata M, Asabe SI, Hirota M, Kimura K, Shimotohno K. Two hepatitis $C$ virus glycoprotein $E 2$ products with different $C$ termini. J Virol 1994; 68: 6215-6222

${ }^{27}$ Mizushima H, Hijikata M, Tanji Y, Kimura K, Shimotohno K. Analysis of N-terminal processing of hepatitis $C$ virus nonstructural protein 2. J Virol 1994; 68: $2731-2734$

${ }^{28}$ Grakoui A, McCourt DW, Wychowski C, Feinstone SM, Rice CM. A second hepatitis C virus-encoded proteinase. Proc Natl Acad Sci USA 1993; 90: 10583-10587

${ }^{29}$ Hijikata M, Mizushima H, Akagi T, Mori S, Kakiuchi N, Kato N, Tanaka T, Kimura K, Shimotohno K. Two distinct proteinase activities required for the processing of a putative nonstructural precursor protein of hepatitis C virus. J Virol 1993; 67: 4665-4675

${ }^{30}$ Love AL, Parge HE, Wickersham JA, Hostomsky Z, Habuka N, Moomaw EW, Adachi T, Hostomska Z. The crystal stucture of hepatitis $C$ virus NS3 proteinase reveals a trypsin-like fold and a structural zinc binding site. Cell 1996; 87: 342

${ }^{31}$ Grakoui A, McCourt DW, Wychowski C, Feinstone SM, Rice CM. Characterization of the hepatitis $C$ virus-encoded serine proteinase: determination of proteinase-dependent polyprotein cleavage sites. J Virol 1993; 67: $2832-2843$

32 Preugschat F, Averett DR, Clarke BE, Porter DJT. A steady state and prestady-state kinetic analysis of the NTPase activity associated with the hepatitis C virus NS3 helicase domain. J Biol Chem 1996; 271: $24449-24457$

${ }^{33}$ Suzich JA, Tamura JK, Palmer-Hill F, Warrener P, Grakoui A, Rice CM, Feinstone SM, Collett MS. Hepatitis C virus NS3 protein polynucleotide-stimulated nucleoside triphosphatase and comparison with the related pestivirus and flavivirus enzymes. J Virol 1993; 67: 6152 -6158

34 Tai CL, Chi WK, Chen DS, Hwang LH. The helicase activity associated with hepatitis C virus nonstructural protein 3 (NS3). J Virol 1996; 70 : $8477-8484$

${ }^{35}$ Di Marco S, Rizzi M, Volpari C, Walsh MA, Narjes F, Colarusso S, De Francesco R, Matassa VG, Sollazzo M. Inhibition of the Hepatitis C Virus NS3/4A Protease. The crystal structures of two protease-inhibitor complexes. J Biol Chem 2000; 275: $7152-7157$

${ }^{36}$ Lin C, Wu JW, Hsiao K, Su MSS. The hepatitis C virus NS4A protein: interactions with the NS4B and NS5A protein. J Virol 1997; 71: 6465-6471

${ }^{37}$ Koch OJ, Bartenschlager R. Modulation of hepatitis C virus NS5A hyperphosphorylation by nonstructural proteins NS3, NS4A, and NS4B. J Virol 1999; 73: 7138 - 7146

38 Kaneko T, Tanji Y, Satoh S, Hijikata M, Asabe S, Kimura K, Shimotohno K. Production of two phosphoproteins from the NS5A region of the hepatitis C viral genome. Biochem Biophys Res Commun 1994; 205: 320-326

${ }^{39}$ Tanji Y, Kaneko T, Satoh S, Shimotohno K. Phosphorylation of hepatitis C virus-encoded nonstructural protein NS5A. J Virol 1995; 69: $3980-3986$

${ }^{40} \mathrm{Hu} \mathrm{KQ}$ Vierling JM, Redeker AG. Viral, host and interferon-related factors modulating the effect of interferon therapy for hepatitis $C$ virus infection. J Viral Hepat 2001; 8: 1- 18

${ }^{41}$ Pawlotsky JM. Hepatitis C virus resistance to antiviral therapy. Hepatology 2000; 32: 889-896

42 Tan SL, Katze MG. How Hepatitis C Virus Counteracts the Interferon Response: The Jury Is Still out on NS5A. Virology 2001; 284: 1-12

${ }^{43}$ Pawlotsky JM, Germanidis G. The non-structural 5A protein of hepatitis C virus. J Viral Hepat 1999; 6: 343-356

${ }^{44}$ Lohmann V, Roos A, Korner F, Koch JO, Bartenschlager R. Biochemical and structural analysis of the NS5B RNA-dependent RNA polymerase of the hepatitis C virus. J Viral Hepat 2000; 7: 167-174

${ }^{45}$ Lohmann V, Körner F, Herian U, Bartenschlager R. Biochemical properties of hepatitis $C$ virus NS5B RNA-dependent RNA polymerase and identification of amino acid sequence motifs essential for enzymatic activity. J Virol 1997; 71: 8416-8428

${ }^{46}$ Yuan ZH, Kumar U, Thomas HC, Wen YM, Monjardino J. Expression, purification, and partial charactarization of HCV RNA polymerase. Biochem Biophys Res Commun 1997; 232: 231 - 235

47 Yamashita T, Kaneko S, Shirota Y, Qin W, Nomura T, Kobayashi K, Murakami S. RNA-dependent RNA polymerase activity of the soluble recombinant hepatitis $C$ virus NS5B protein truncated at the C-terminal region. J Biol Chem 1998; 273: 15479-15486

48 Behrens SE, Tomei L, De Francesco R. Identification and properties of the RNA-dependent RNA polymerase of hepatitis C virus. EMBO 1996; 15: $12-22$ 
${ }^{49} \mathrm{Al} \mathrm{RH}$, Xie Y, Wang Y, Hagedorn CH. Expression of recombinant hepatitis $C$ virus non-structural protein $5 \mathrm{~B}$ in Escherichia coli. Virus Res 1998; 53: 141 - 149

${ }^{50}$ Lau JY, Mizokami M, Davis GL, Kolberg JA, Urdea MS, Orito E, Polito A, DiNello R, Quan S. Relationship between the presence of circulating anti-GOR and hepatitis C viremia/genotype. J Hepatol 1995; 22: 707

${ }^{51}$ Taliani G, Lecce R, Badolato MC, Bozza A, Poliandri G, Furlan C, Bruni R, Clementi C, De Bac C. Anti-GOR antibodies in anti-hepatitis $C$ virus positive subjects with and without virus replication and liver disease. J Hepatol 1994; 20: 845

52 Shimizu YK, Hijikata M, Iwamoto A, Alter HJ, Purcell RH, Yoshikura H. Neutralizing antibodies against hepatitis $C$ virus and the emergence of neutralization escape mutant viruses. J Virol 1994; 68: 1494-1500

${ }^{53}$ Quiroga JA, van Binsbergen J, Wang CY, Pardo M, Navas S, Trines C, Herrero M, Carreno V. Immunoglobulin M antibody to hepatitis C virus core antigen: correlations with viral replication, histological activity, and liver disease outcome. Hepatology 1995; 22: 1635-1640

${ }^{54}$ Quiroga JA, Campillo ML, Catillo I, Bartolome J, Porres JC, Carreno V. IgM antibody to hepatitis $\mathrm{C}$ virus in acute and chronic hepatitis $\mathrm{C}$. Hepatology 1991; 14: $38-43$

${ }^{55}$ Gerlach JT, Diepolder HM, Jung MC, Gruener NH, Schraut WW, Zachoval R, Hoffmann R, Schirren CA, Santantonio T, Pape GR. Recurrence of hepatitis $C$ virus after loss of virus-specific CD4(+) T-cell response in acute hepatitis C. Gastroenterology 1999; 117: 933-941

${ }^{56}$ Grüner NH, Gerlach TJ, Jung MC, Diepolder HM, Schirren CA, Schraut WW, Hoffmann R, Zachoval R, Santantonio T, Cucchiarini M, Cerny A, Pape GR. Association of Hepatitis C Virus-Specific CD8+ T Cells with Viral Clearance in Acute Hepatitis C. J Infect Dis 2000; 181: $1528-1536$

57 Rehermann B, Chang KM, McHutchison JG, Kokka R, Houghton M, Chisari FV. Quantitative analysis of the peripheral blood cytotoxic T lymphocyte response in patients with chronic hepatitis $C$ virus infection. J Clin Invest 1996; 98: $1432-1440$

58 Rehermann B, Chang KM, McHutchison J, Kokka R, Houghton M, Rice $\mathrm{CM}$, Chisari FV. Differential cytotoxic T-lymphocyte responsiveness to the hepatitis B and C viruses in chronically infected patients. J Virol 1996; 70: $7092-7102$

${ }^{59}$ Grüner NH, Lechner F, Jung MC, Diepolder H, Gerlach T, Lauer G, Walker B, Sullivan J, Phillips R, Pape GR, Klenerman P. Sustained dysfunction of antiviral cd8(+) t lymphocytes after infection with hepatitis $c$ virus. J Virol 2001; 75: 5550-5558

${ }^{60}$ Cabot B, Martell M, Esteban JI, Sauleda S, Otero T, Esteban R, Guardia J, Gomez J. Nucleotide and amino acid complexity of hepatitis $C$ virus quasispecies in serum and liver. J Virol 2000; 74: 805-811

${ }^{61}$ Rehermann B, Chisari FV. Cell mediated immune response to the hepatitis C virus. Curr Top Microbiol Immunol 2000; 242: 299-325

${ }^{62}$ Diepolder HM, Hoffmann RM, Gerlach JT, Zachoval R, Jung MC, Pape GR. Immunopathogenesis of HCV infection. Curr Stud Hematol Blood Transfus 1998; $135-151$

63 Owerbach D, Rutter WJ, Shows TB, Gray P, Goeddel DV, Lawn RM. Leukocyte and fibroblast interferon genes are located on human chromosome 9. Proc Natl Acad Sci USA 1981; 78: $3123-3127$

${ }^{64}$ Foster GR, Rodrigues O, Ghouze F, Schulte-Frohlinde E, Testa D, Liao MJ, Stark GR, Leadbeater L, Thomas HC. Different relative activities of human cell-derived interferon-alpha subtypes: IFN-alpha 8 has very high antiviral potency. J Interferon Cytokine Res 1996; 16: 1027 - 1033

65 Pestka S, Langer JA, Zoon KC, Samuel CE. Interferons and their actions. Annu Rev Biochem 1987; 56: 727-777

${ }^{66}$ Lengyel P. Biochemistry of interferons and their actions. Annu Rev Biochem 1982; 51: 251-282

67 Pfeffer LM, Dinarello CA, Heberman RB, Williams BRG, Borden EC, Bordens R, Walter MR, Nagabhushan TL, Trotta PP, Pestka S. Biological properties of recombinant a-interferons: 40th anniversary of the discovery of interferons. Cancer Res 1998; 58: 2489-2499

${ }^{68}$ Farrell GC, Bacon BR, Goldin RD. Lymphoblastoid interferon alfa-n1 improves the long-term response to a 6-month course of treatment in chronic hepatitis $C$ compared with recombinant interferon alfa- $2 b$ : results of an international randomized controlled trial. Clinical Advisory Group for the Hepatitis C Comparative Study. Hepatology 1998; 27: $1121-1127$

${ }^{69}$ Cacopardo B, Benanti F, Brancati G, Romano F, Nunnari A. Leucocyte interferon-alpha retreatment for chronic hepatitis $C$ patients previously intolerant to other interferons. J Viral Hepat 1998; 5: 333-339

${ }^{70}$ Isaacs A, Lindenmann J. Virus interference. I. The interferon. Proc R Soc Lond Ser B 1957; 147: 258-267
${ }^{71}$ Stark GR, Kerr IM, Williams BRG, Silverman RH, Schreiber RD. How cells respond to interferons. Annu Rev Biochem 1998; 67: 227-264

72 Witkowski JT, Robins RK, Sidwell RW, Simon LN. Design, synthesis, and broad spectrum antiviral activity of 1-b-D-ribofuranosyl1,2,4-triazole-3-carboxamide and related nucleosides. J Med Chem 1972; $15: 1150-1154$

${ }^{73}$ Sidwell RW, Huffman JH, Khare GP, Allen LB, Witkowski JT, Robins RK. Broad-spectrum antiviral activity of Virazole: 1-b-D-ribofuranosyl1,2,4-triazole-3-carboxamide. Science 1972; 177: 705-706

${ }^{74}$ Glue P. The clinical pharmacology of ribavirin. Semin Liv Dis 1999; 19 (Suppl 1): $17-24$

${ }^{75}$ Chang TW, Heel RC. Ribavirin and inosiplex: a review of their present status in viral diseases. Drugs 1981; 22: $111-128$

${ }^{76}$ Goswami BB, Borek E, Sharma OK, Fujitaki J, Smith RA. The broad spectrum antiviral agent ribavirin inhibits capping of mRNA. Biochem Biophys Res Commun 1979; 89: 830-836

77 Wray SK, Gilbert BE, Noall MW, Knight V. Mode of action of ribavirin: effect of nucleotide pool alteration on influenza virus ribonucleoprotein synthesis. Antiviral Res 1985; 5: 29-37

78 Eriksson B, Helgstrand E, Johansson NG, Larsson A, Misiorny A, Noren JO, Philipson L, Sternberg K, Stening G, Stridh S, Oberg B. Inhibition of influenza virus ribonucleic acid polymerase by ribavirin triphosphate. Antimicrob Agents Chemother 1977; 11: 946 - 951

${ }^{79}$ Peavy DL, Powers CN, Knight V. Inhibition of murine plaque-forming cell responses in vivo by ribavirin. J Immunol 1981; 126: 861 - 864

${ }^{80}$ Powers CN, Peavy DL, Knight V. Selective inhibition of functional lymphocyte subpopulations by ribavirin. Antimicrob Agents Chemother 1982; 22: $108-114$

${ }^{81}$ Hultgren C, Milich DR, Weiland O, Sällberg M. The antiviral compound ribavirin modulates the T helper (Th)1/Th2 subset balance in hepatitis B and C virus-specific immune response. J Gen Virol 1998; 79: $2381-2391$

82 Di Bisceglie AM, Conjeevaram HS, Fried MW, Sallie R, Park Y, Yurdaydin C, Swain M, Kleiner DE, Mahaney K, Hoofnagle JH. Ribavirin as therapy for chronic hepatitis C. A randomized, double-blind, placebocontrolled trial. Ann Intern Med 1995; 123: 897-903

${ }^{83}$ Zeuzem S, Schmidt JM, Lee JH, von Wagner M, Teuber G, Roth WK. Hepatitis $C$ virus dynamics in vivo: effect of ribavirin and interferon alfa on viral turnover. Hepatology 1998; 28: 245-252

${ }^{84}$ Lee JH, von Wagner M, Roth WK, Teuber G, Sarrazin C, Zeuzem S. Effect of ribavirin on virus load and quasispecies distribution in patients infected with hepatitis C virus. J Hepatol 1998; 29: 29-35

${ }^{85}$ Fried MW, Fong TL, Swain MG, Park Y, Beames MP, Banks SM, Hoofnagle JH, Di Bisceglie AM. Therapy of chronic hepatitis B with a 6-month course of ribavirin. J Hepatol 1994; 21: 145-150

86 Poynard T, Marcellin P, Lee SS, Niederau C, Minuk GS, Ideo G, Bain V, Heathcote J, Zeuzem S, Trepo C, Albrecht J. Randomised trial of interferon alpha2b plus ribavirin for 48 weeks or for 24 weeks versus interferon alpha2b plus placebo for 48 weeks for treatment of chronic infection with hepatitis C virus. International Hepatitis Interventional Therapy Group (IHIT). Lancet 1998; 352: 1426 - 1432

87 Enomoto N, Sakuma I, Asahina Y, Kurosaki M, Murakami T, Yamamoto C, Ogura Y, Izumi N, Marumo F, Sato C. Mutations in the nonstructural protein $5 \mathrm{~A}$ gene and response to interferon in patients with chronic hepatitis C virus 1b infection. N Engl J Med 1996; 334: 77-81

88 Zeuzem S, Lee JH, Roth WK. Mutations in the nonstructural 5A gene of European hepatitis $C$ virus isolates and response to interferon alfa. Hepatology 1997; 25: 740-744

${ }^{89}$ Squadrito G, Leone F, Sartori M, Nalpas B, Berthelot P, Raimondo G, Pol $S$, Brechot $C$. Mutations in the nonstructural $5 A$ region of hepatitis $C$ virus and response of chronic hepatitis $C$ to interferon alfa. Gastroenterology 1997; 113: 567-572

${ }^{90}$ Hofgärtner WT, Polyak SJ, Sullivan DG, Carithers Jr RL, Gretch DR. Mutations in the NS5A gene of hepatitis C virus in North American patients infected with HCV genotype 1a or 1b. J Med Virol 1997; 53 $118-126$

91 Sarrazin C, Berg T, Lee JH, Teuber G, Dietrich CF, Roth WK, Zeuzem S. Improved correlation between multiple mutations within the NS5A region and virological response in European patients chronically infected with hepatitis $C$ virus type $1 \mathrm{~b}$ undergoing combination therapy. J Hepatol 1999; 30: 1004-1013

92 Sarrazin C, Berg T, Lee JH, Rüster B, Kronenberger B, Roth WK, Zeuzem $\mathrm{S}$. Mutations in the protein kinase-binding domain of the NS5A protein in patients infected with hepatitis $C$ virus type $1 \mathrm{a}$ are associated with treatment response. J Infect Dis 2000; 181: $432-441$ 
${ }^{93}$ Murakami T, Enomoto N, Kurosaki M, Izumi N, Marumo F, Sato C. Mutations in nonstructural protein $5 \mathrm{~A}$ gene and response to interferon in hepatitis C virus genotype 2 infection. Hepatology 1999; 30: $1045-1053$

${ }^{94}$ Sarrazin C, Kornetzky I, Rüster B, Lee JH, Kronenberger B, Bruch K, Roth WK, Zeuzem S. Mutations within the E2 and NS5A protein in patients infected with hepatitis $C$ virus type $3 \mathrm{a}$ and correlation with treatment response. Hepatology 2000; 31: 1360-1370

${ }^{95}$ Gale Jr M, Blakely CM, Kwieciszewski B, Tan SL, Dossett M, Tang NM, Korth MJ, Polyak SJ, Gretch DR, Katze MG. Control of PKR protein kinase by hepatitis $C$ virus nonstructural $5 \mathrm{~A}$ protein: molecular mechanisms of kinase regulation. Mol Cell Biol 1998; 18: 5208-5218

${ }^{96}$ Polyak SJ, Paschal DM, McArdle S, Gale MJ Jr, Moradpour D, Gretch DR. Characterization of the effects of hepatitis $C$ virus nonstructural $5 \mathrm{~A}$ protein expression in human cell lines and on interferon-sensitive virus replication. Hepatology 1999; 29: $1262-1271$
${ }^{97}$ Paterson M, Laxton CD, Thomas HC, Ackrill AM, Foster GR. Hepatitis C virus NS5A protein inhibits interferon antiviral activity, but the effects do not correlate with clinical response. Gastroenterology 1999; 117: $1187-1197$

${ }^{98}$ Francois C, Duverlie G, Rebouillat D, Khorsi H, Castelain S, Blum HE, Gatignol A, Wychowski C, Moradpour D, Meurs EF. Expression of hepatitis $C$ virus proteins interferes with the antiviral action of interferon independently of PKR-mediated control of protein synthesis. J Virol 2000; 74: 5587-5596

${ }^{99}$ Taylor DR, Shi ST, Romano PR, Barber GN, Lai MMC. Inhibition of the interferon-inducible protein kinase PKR by HCV E2 protein. Science 1999; 285: $107-110$ 